\title{
A Pragmatic Approach to Prevent Premature Failure of Ultrasonically Guided Catheter (Cannula)
}

\author{
B.M. Munasinghe ${ }^{1^{*}}$, U.P.M. Fernando ${ }^{2}$ \\ ${ }^{1}$ Acting Consultant Anaesthetist, District General Hospital, Mannar, Sri Lanka, ${ }^{2}$ Medical Officer, \\ National Blood Transfusion Service, Sri Lanka
}

\section{Dear editor,}

Ultrasound guided peripheral venous cannulation $(\mathrm{Pvc})$ is a relatively safer alternative considering lesser invasiveness and higher practicality in cases of difficult peripheral venous access.

Superiority of ultrasound guidance for $\mathrm{Pvc}$ compared to traditional method has already been demonstrated. ${ }^{1}$ The demerits, importantly, premature cannula failure (PCF) are found to be higher in ultrasonically placed peripheral cannula in relation to the traditional technique. (45-56\% vs $19-25 \%$ respectively). ${ }^{2,3}$

Infiltration is the leading cause of $\mathrm{PCF}^{2,3}$, which is the focus of this monograph where methods to avoid the former are briefly reviewed.

Infiltration occurs when infused drugs and fluids accumulate in surrounding tissue. The size and depth of the veins relative to the size of the cannula, in-situ thrombi, length of the catheter inside the lumen of the vein and the use of hyperosmolar solutions are implicated. ${ }^{4}$ Smaller the size of the vein, higher the risk of infiltration. ${ }^{4}$ It is recommended to choose veins with an antero-posterior diameter of at least

*Correspondence: B. M. Munasinghe

E mail: malakafmp@gmail.com

https://orcid.org/0000-0001-8373-4752

Received: 14/07/2021

Accepted: 26/09/2021

DOI: https://doi.org/10.4038/slja.v29i2.8893
$4 \mathrm{~mm}$ in some studies ${ }^{3}$, although much smaller veins could be cannulated with appropriately sized catheter. The ratio between the external diameter of cannula to antero-posterior diameter of vein comes to play in minimizing infiltration, as essentially a ratio of $<0.3$ or catheter occupying less than one-third of the area of the venous lumen is associated with reduced incidence of infiltration. ${ }^{3}$ Similarly, increased length of the catheter inside the lumen, lessen the risk of infiltration. ${ }^{2-4}$ Ultra-long or midline catheters and use of superficial veins ${ }^{3}$ have been proposed in view of increasing the in-situ length. The plane of ultrasonic view, either long-axis or short-axis, was not found to be superior to one another in averting infiltration. ${ }^{1}$ The figure 1 illustrates an ultrasonically placed peripheral cannula without PCF.

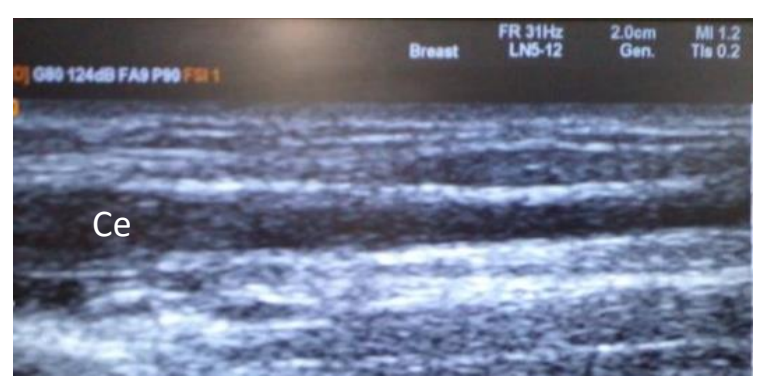

Figure 1a

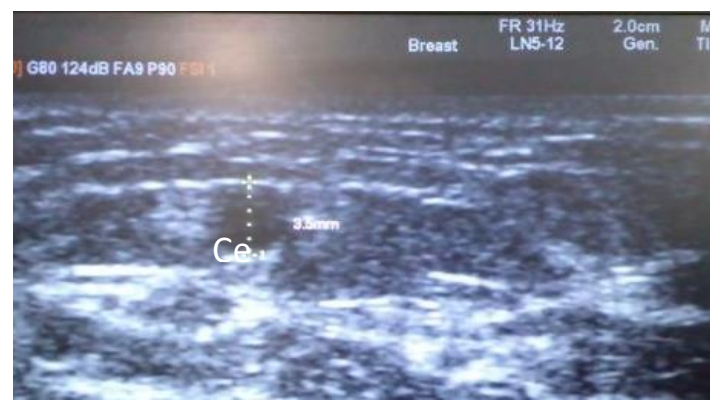

Figure $1 b$ 


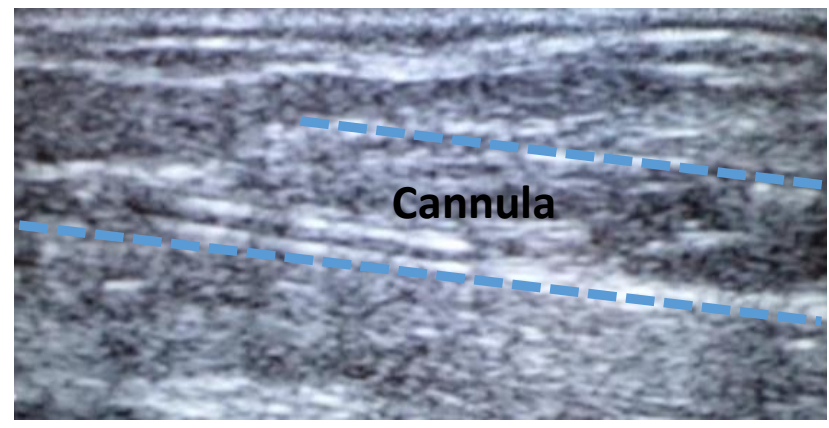

Figure 1c

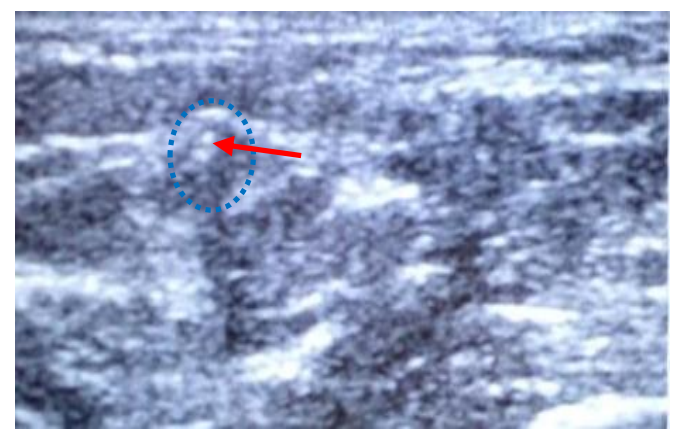

Figure 1d

Figure 1. Placement of a $20 G$ cannula (external diameter 1.0mm) in Cephalic vein (Ce) for a difficult peripheral venous access under ultrasound guidance. 1a, Long axis view; $1 b$, short axis view showing an anteroposterior diameter of $3.5 \mathrm{~mm}$ of $\mathrm{Ce}$; $1 \mathrm{c}$, successfully placed cannula inside the vein (blue dotted) in long axis; 1d, cannula (red arrow) inside the vein (blue oval) in short axis

Some authors have suggested a 'bundle' to minimize ultrasound guided PCF, consisting of 'Pre-scan' to assess vein diameter, 'post-scan' to assess cannula tip position, and use of polyurethane catheters. ${ }^{5}$ The association of Anaesthetists of Great Britain and Ireland recommends early use of ultrasound guided peripheral cannulations for difficult venous access. ${ }^{1}$ The learning curve seems to be shorter.

Thus, selection of appropriate veins and catheters would improve the in-situ duration abating PCF and related complications.

\section{References}

1. van Loon FHJ, Buise MP, Claassen JJF, Dierick-van Daele ATM, Bouwman ARA. Comparison of ultrasound guidance with palpation and direct visualisation for peripheral vein cannulation in adult patients: a systematic review and meta-analysis. British journal of anaesthesia. 2018; 121(2):358-66.

2. Bahl A, Hang B, Brackney A, Joseph S, Karabon P, Mohammad A, et al. Standard long IV catheters versus extended dwell catheters: A randomized comparison of ultrasound-guided catheter survival. The American Journal of Emergency Medicine. 2019; 37(4):715-21.

3. Blanco P. Ultrasound-guided peripheral venous cannulation in critically ill patients: a practical guideline. The Ultrasound Journal. 2019; 11(1):27.

4. Tanabe H, Takahashi $\mathrm{T}$, Murayama R, Yabunaka K, Oe M, Matsui Y, et al. Using Ultrasonography for Vessel Diameter Assessment to Prevent Infiltration. Journal of infusion nursing : the official publication of the Infusion Nurses Society. 2016; 39(2):105-11.

5. Takahashi, T., Murayama, R., Abe-Doi, M. et al. Preventing peripheral intravenous catheter failure by reducing mechanical irritation. Sci $\begin{array}{llll}\text { Rep } & 10, & 1550 \quad \text { (2020). }\end{array}$ https://doi.org/10.1038/s41598-019-56873-2 